\title{
28 Research Square \\ Syntheses of MnW12/TiO2 Microflowers and Nanorods for Photocatalytic H2 Evolution
}

\author{
Ningning Guo \\ Henan University \\ Shixian Liu \\ Henan University \\ Niuniu Zhang \\ Henan University \\ Xia Wu \\ Henan University \\ Guan Wang ( $\nabla$ wangguan@henu.edu.cn ) \\ Henan University https://orcid.org/0000-0002-0082-1875 \\ Yuan Zhao \\ Henan University
}

\section{Nano Express}

Keywords: isopolyoxometallate, controlling morphology, photocatalytic hydrogen generation

Posted Date: March 13th, 2021

DOl: https://doi.org/10.21203/rs.3.rs-304603/v1

License: (c) (1) This work is licensed under a Creative Commons Attribution 4.0 International License.

Read Full License 


\section{Abstract}

$\mathrm{MnW}_{12} / \mathrm{TiO}_{2}$ microflower has been successfully synthesized by the one-pot method and the microflower could be converted to nanorods by thermal treatment. The hydrogen evolution efficiency of $\mathrm{MnW}_{12} / \mathrm{TiO}_{2}$ nanorods is higher than that of $\mathrm{MnW}_{12} / \mathrm{TiO}_{2}$ microflowers by means of the photocatalysis test. These results suggest that the photocatalytic property of $\mathrm{MnW}_{12} / \mathrm{TiO}_{2}$ could be enhanced by controlling morphology. In addition, massive control experiments have been conducted to explore the effect factors of morphologies. Therefore, the successful preparations in this work not only open up new directions for the structural diversity of isopolyoxometallate based nano/micro materials, but also provide us with an irradiative way to increase the photocatalytic performance of $\mathrm{POM} / \mathrm{TiO}_{2}$ nano/micro composite.

\section{Introduction}

Polyoxometallates (POMs) as a fascinating species of metal-oxygen clusters have a wide range of potential applications due to their diverse structures and tunable properties in catalysis, materials and photoluminescence, etc [1-4]. As a unique branch of POM chemistry, POM based nano/micro materials remain less explored to date in comparison with traditional single crystal POM compounds. With the development of nanotechnology, the morphology, component and size of POM based nano/micro materials can be tuned easily through artificial methods. As a consequence, many researchers have been making significant efforts to explore in this field, and a variety of POM based nano/micro materials have been addressed [5-10]. In 2011, Cronin et al. reported a new phenomenon, namely, the growth of hollow mineral tubular architectures, and this may have significance in the interpretation of the architectures found in the fossil record that have been to date attributed to biological processes [7]. After this, Mnbased heteropolytungstate microspheres were prepared by Chattopadhyay and coworkers using a unique solvothermal method [11].

To the best of our knowledge, titanium dioxide $\left(\mathrm{TiO}_{2}\right)$ is an important photocatalyst and has been widely investigated due to its advantages such as relatively low-cost, good chemical stability and higher oxidation potential [12-17]. Zou's group fabricates $\mathrm{TiO}_{2} \mathrm{p}$-n homojunction for photoelectrochemical and photocatalytic hydrogen generation [18]. Yi and coworkers reported $\mathrm{W}_{2} \mathrm{C} @ \mathrm{C} / \mathrm{TiO}_{2}$ heterojunction architecture with efficient solar-light-driven hydrogen generation [19].

However, there are relatively few studies on the synthesis and properties of $\mathrm{POMs} / \mathrm{TiO}_{2}$ materials. In 2013, Bansal's group fabricated $\mathrm{TiO}_{2}$-POM-bimetal nanocomposites for improved surface enhanced Raman scattering and solar light photocatalysis [20]. Wang et al. synthesized $\mathrm{POM} / \mathrm{TiO}_{2} / \mathrm{Ag}$ composite nanofibers with enhanced photocatalytic performance under visible light [21]. Lan's group reported $\mathrm{POM} / \mathrm{TiO}_{2}$ Fenton-like photocatalysts with rearranged oxygen vacancies for enhanced synergetic degradation [22]. From these literatures, the morphology is an important factor that has great impacts on the performance of photocatalyst. Because the morphology affects the specific surface area, separation efficiency and migration rate of photogenerated charges. 
From these perspectives, how to enhance the performance of photocatalyst through morphology control has become a goal pursued by our group. In this work, $\mathrm{MnW}_{12} / \mathrm{TiO}_{2}$ microflower has been successfully prepared by a one-pot method through mild conditions. Fortunately, $\mathrm{MnW}_{12} / \mathrm{TiO}_{2}$ microflower could be converted to nanorods by thermal treatment at $550{ }^{\circ} \mathrm{C}$. Under the photocatalysis test, the hydrogen evolution efficiency of $\mathrm{MnW}_{12} / \mathrm{TiO}_{2}$ nanorods is higher than that of $\mathrm{MnW}_{12} / \mathrm{TiO}_{2}$ microflowers. These results indicate that the performance of photocatalytic could be tuned by controlling morphology. Meanwhile, a large number of control experiments have been carried out to explore the effect factors of morphologies. Therefore, this work not only enrich the diversity of isopolyoxometallate based nano/micro materials, but also find an enlightening way to improve the photocatalytic efficiency of $\mathrm{POM} / \mathrm{TiO}_{2}$ nano/micro composite.

\section{Experimental}

\subsection{Materials and methods}

$\mathrm{TiO}_{2}$ (P25) was purchased from Degussa. All chemicals were reagent-grade and used without further purification. The materials have been fully characterized by transmission electron microscope (TEM), scanning electron microscopy (SEM), energy dispersive X-ray spectroscopy (EDX), X-ray powder diffraction (XRD), IR spectroscopy, X-ray photoelectron spectroscopy (XPS), thermogravimetry (TG). XRD (Bruker D8 Advance, Bruker optics Instruments company, Karlsruhe, Germany) was performed using a instrument with $\mathrm{Cu}$ Ka radiation $(\lambda=1.5418 \AA$ ) . The TEM images were obtained using a transmission electron microscope (JEM-2100F囚Electronics Co. LTD, Tokyo, Japan). The SEM images and EDX spectrum were obtained using a scanning electron microscope (JSM-7610F囚Electronics Co. LTD, Tokyo, Japan) with an acceleration voltage of $10 \mathrm{kV}$. The IR spectra were obtained via an Avatar 360 Fourier transform infrared spectrophotometer (Bruker optics Instruments company, Karlsruhe, Germany) using $\mathrm{KBr}$ pellets in the range of $4000-400 \mathrm{~cm}-1$. XPS was conducted using a Thermo ESCALAB 250XI spectrometer (Thermo Fisher Scientific, Massachusetts, USA). The TG curve was obtained on the STA449F5 thermo-gravimetric analyzer (Netzsch, Selb, Germany).

\subsection{Synthesis of $\mathrm{MnW}_{12}$ Microflower}

$\mathrm{Na}_{2} \mathrm{WO}_{4} \cdot 2 \mathrm{H}_{2} \mathrm{O}(3.00 \mathrm{~g}, 9.62 \mathrm{mmol})$ was dissolved in $30 \mathrm{~mL}$ of distilled water, heated to $80^{\circ} \mathrm{C}$ with stirring, and boric acid $(0.10 \mathrm{~g}, 1.62 \mathrm{mmol})$ was added to the solution. Then, after adjusting the $\mathrm{pH}$ of the solution to 7.0 with dilute $\mathrm{HCl}$, a small amount of aqueous solution containing $\mathrm{MnCl}_{2} \cdot 4 \mathrm{H}_{2} \mathrm{O}(0.40 \mathrm{~g}, 2.00 \mathrm{mmol})$ was slowly added dropwise, and after the dropping, it was heated and stirred for the first 30 minutes. Then, after adjusting the $\mathrm{pH}$ of the solution to 6.0 with dilute $\mathrm{HCl}$, it was heated and stirred for the second 30 minutes, finally cooled at room temperature for $1 \mathrm{hr}$. The $\mathrm{MnW}_{12}$ microflowers were collected by centrifugation and washed with water and ethanol to remove excess reagents. $\mathrm{MnW}_{12}$ microflowers 
changed into different morphologies after calcination at different temperatures and atmospheres for 2 hrs.

\subsection{Related Control Experiments}

To explore the influence of different counter cations on the morphology, the synthetic procedure was identical to that of $\mathrm{MnW}_{12}$ microflowers, but $\mathrm{MnCl}_{2} \cdot 4 \mathrm{H}_{2} \mathrm{O}$ was replaced by $\mathrm{NH}_{4} \mathrm{Cl}, \mathrm{KCl}, \mathrm{N}\left(\mathrm{C}_{4} \mathrm{H}_{9}\right)_{4} \mathrm{Br}, \mathrm{CsCl}$, respectively.

To explore the influence of different manganese salts on the morphology of $\mathrm{MnW}_{12}$ microflowers, the synthetic procedure was identical to that of $\mathrm{MnW}_{12}$ microflowers, but $\mathrm{MnCl}_{2} \cdot 4 \mathrm{H}_{2} \mathrm{O}$ was replaced by $\mathrm{Mn}(\mathrm{Ac})_{2}, \mathrm{Mn}\left(\mathrm{ClO}_{4}\right)_{2}, \mathrm{MnSO}_{4}, \mathrm{Mn}\left(\mathrm{NO}_{3}\right)_{2}$, respectively.

To explore the influence of adding different amounts of PEG4000 on the $\mathrm{MnW}_{12}$ microflowers, the synthetic procedure was identical to that of $\mathrm{MnW}_{12}$ microflowers, but different amounts of PEG4000 were added to the solution after boric acid.

To explore the influence of different stirring times on the appearance of $\mathrm{MnW}_{12}$ microflowers, the synthetic procedure was identical to that of $\mathrm{MnW}_{12}$ microflowers, but the first 30 minutes were changed to $10 \mathrm{~min}, 1 \mathrm{hr}, 2 \mathrm{hrs}$, respectively.

To explore the influence of different amount of $\mathrm{MnCl}_{2}$ on the appearance of $\mathrm{MnW}_{12}$ microflowers, the synthetic procedure was identical to that of $\mathrm{MnW}_{12}$ microflowers, but the amount of $\mathrm{MnCl}_{2}$ were changed to $1 \mathrm{mmol}, 4 \mathrm{mmol}$, respectively.

\subsection{Synthesis of $\mathrm{MnW}_{12} / \mathrm{TiO}_{2}$ Microflowers}

$\mathrm{Na}_{2} \mathrm{WO}_{4} \cdot 2 \mathrm{H}_{2} \mathrm{O}(3.00 \mathrm{~g}, 9.62 \mathrm{mmol})$ was dissolved in $30 \mathrm{~mL}$ of distilled water, heated to $80^{\circ} \mathrm{C}$ with stirring, and boric acid $(0.10 \mathrm{~g}, 1.62 \mathrm{mmol})$ was added to the solution. Then, after a small amount of aqueous solution containing $\mathrm{TiO}_{2}(0.12 \mathrm{~g}, 1.50 \mathrm{mmol})$ was slowly added dropwise, adjusting the $\mathrm{pH}$ of the solution to 7.0 with dilute $\mathrm{HCl}$, a small amount of aqueous solution containing $\mathrm{MnCl}_{2} \cdot 4 \mathrm{H}_{2} \mathrm{O}(0.40 \mathrm{~g}, 2.00 \mathrm{mmol})$ was slowly added dropwise, and after the dropping, it was heated and stirred for the first 30 minutes. Then, after adjusting the $\mathrm{pH}$ of the solution to 6.0 with dilute $\mathrm{HCl}$, it was heated and stirred for the second 30 minutes, and finally cooled at room temperature for $1 \mathrm{hr}$. $\mathrm{MnW}_{12} / \mathrm{TiO}_{2}$ microflowers were collected by centrifugation and washed with water and ethanol to remove excess reagents.

\subsection{Synthesis of $\mathrm{MnW}_{12} / \mathrm{TiO}_{2}$ Nanorods}


The $\mathrm{MnW}_{12} / \mathrm{TiO}_{2}$ microflowers $(3 \mathrm{~g})$ was placed in a porcelain boat and transferred to a tube furnace at room temperature. Then the temperature was ramped to $550^{\circ} \mathrm{C}$ at a speed of $5^{\circ} \mathrm{C} \mathrm{min}-1$ and maintained for $2 \mathrm{~h}$ under air atmosphere. After cooling to room temperature, $\mathrm{MnW}_{12} / \mathrm{TiO}_{2}$ nanorods were collected.

\subsection{Photocatalytic Hydrogen Production}

The $\mathrm{H}_{2}$ evolution experiments were performed in a closed gas-circulating system CEL-PAEM-D8 (China Education Au-light Co., Ltd, Beijing, China) equipped with an external illumination Pyrex reaction vessel (total volume $100 \mathrm{~mL}$ ) with a magnetic stirrer for vigorous stirring and analyzed by using an automatic $\mathrm{H}_{2}$ monitoring system. The vessel was filled with a solution containing a sacrificial electron donor $\mathrm{CH}_{3} \mathrm{OH}$ $(25 \mathrm{~mL}), \mathrm{H}_{2} \mathrm{O}(25 \mathrm{~mL}), \mathrm{H}_{2} \mathrm{PtCl}_{6}(0.012 \mathrm{~g})$ and different catalysts. The reaction was tested using a $300 \mathrm{~W}$ Xe light $(350-780 \mathrm{~nm})$ and the system was evacuated $(-0.1 \mathrm{MPa})$ before opening the Xe light. The produced $\mathrm{H}_{2}$ was analyzed by a gas chromatography (GC7900) with a TCD using Ar as the carrier gas.

\section{Results And Discussion}

In the past two decades, many researchers have been working on the morphology and composition of POM based nano/micro materials. However, the progress shows slower in comparison with traditional single-crystal compounds. In addition, morphologies of POM based nano/micro materials are not abundant, compared with other nano/micro materials. Only few morphologies have been characterized, such as polyhedron, tube, wire and spheres. As shown in Scheme 1, the materials based on isopolyoxometallate are rarely reported in recent years. As a unique branch of POM compound, isopolyoxometallate materials lack of sufficient concern. Finally, the controllable synthesis and photocatalytic hydrogen production properties of $\mathrm{POM} / \mathrm{TiO}_{2}$ nano/micro composite are rarely studied until now. Therefore, we are making great efforts to explore the design and syntheses of isopolyoxometallate based material and research the photocatalytic hydrogen production. Then the combination of $\mathrm{MnW}_{12}$ and $\mathrm{TiO}_{2}$ would create new functional material.

\subsection{SEM and TEM images}

First of all, Scheme S1 shows a schematic of the synthetic processes used to prepare the $\mathrm{MnW}_{12}$ microflower. During the procedure, $\mathrm{Mn}^{2+}$ plays the role as counter ions which would be combined with polyanions. As shown in Figure 1, the $\mathrm{MnW}_{12}$ microflower is composed of uniform flower-like morphology. After statistic of 60 particles, the diameter is distributed in the range of $1.5-1.8 \mu \mathrm{m}$ and the average diameter is around $1.55 \mu \mathrm{m}$ (Figure 1a, inset). Figure 1c- $d$ show the typical transmission electron microscope (TEM) and the high resolution TEM (HRTEM) images of $\mathrm{MnW}_{12}$ microflower. The flower-like morphology of $\mathrm{MnW}_{12}$ is also verified by TEM and the d-spacing $(0.3 \mathrm{~nm})$ of the $\mathrm{MnW}_{12}$ microflower is observed by HRTEM. The novel flower-like morphology based on $\mathrm{W}_{12}$ was currently rarely reported, and this result was far beyond our expectation. Thus, great efforts were also put into studying 
the different variables in the formation of the materials. Scheme S2 shows the summary of morphology changes based on $\left[\mathrm{H}_{2} \mathrm{~W}_{12} \mathrm{O}_{40}\right]^{6-}$ (referred as ' $\mathrm{W}_{12}$ ' for short) in this work. This shows POM based nano/micro materials based on $\mathrm{W}_{12}$ have great potential in morphology and performance, and are worthy of exploration and research.

In the process of synthesizing $\mathrm{MnW}_{12}, \mathrm{TiO}_{2}$ is doped to obtain $\mathrm{MnW}_{12} / \mathrm{TiO}_{2}$ microflowers (Figure 2a), which are calcined to obtain $\mathrm{MnW}_{12} / \mathrm{TiO}_{2}$ nanorods (Figure 2b). As shown in Figure 2a, although the morphology of $\mathrm{MnW}_{12}$ is slightly changed due to the addition of $\mathrm{TiO}_{2}, \mathrm{MnW}_{12} / \mathrm{TiO}_{2}$ still maintains the morphology of microflowers. To our astonishment, $\mathrm{MnW}_{12} / \mathrm{TiO}_{2}$ microflowers can be transformed to $\mathrm{MnW}_{12} / \mathrm{TiO}_{2}$ nanorods by thermal treatment at $550{ }^{\circ} \mathrm{C}$ for $2 \mathrm{hrs}$. The two different morphologies of $\mathrm{MnW}_{12} / \mathrm{TiO}_{2}$ are rare in $\mathrm{POM} / \mathrm{TiO}_{2}$ nano/micro composite materials, which also lay the foundation for the different photocatalytic properties. Figure $2 \mathrm{c}-\mathrm{d}$ show the typical transmission electron microscope (TEM) and the high resolution TEM (HRTEM) images of $\mathrm{MnW}_{12} / \mathrm{TiO}_{2}$ microflowers and $\mathrm{MnW}_{12} / \mathrm{TiO}_{2}$ nanorods. As shown in Figure $2 \mathrm{c}$ and Figure $2 \mathrm{~d}$ (inset, left), the $\mathrm{d}$-spacing $(0.24 \mathrm{~nm})$ of the $\mathrm{MnW}_{12} / \mathrm{TiO}_{2}$ microflowers and the d-spacing $(0.3 \mathrm{~nm})$ of the $\mathrm{MnW}_{12} / \mathrm{TiO}_{2}$ nanorods are observed by HRTEM, which is according to that of $\mathrm{MnW}_{12}$ microflower. As depicted in Figure $2 \mathrm{c}$ and Figure $2 \mathrm{~d}$ (inset, right), the other $\mathrm{d}$ spacing $(0.35 \mathrm{~nm})$ of the $\mathrm{MnW}_{12} / \mathrm{TiO}_{2}$ microflowers and the other $\mathrm{d}$-spacing $(0.39 \mathrm{~nm})$ of the $\mathrm{MnW}_{12} / \mathrm{TiO}_{2}$ nanorods can be readily indexed to the $\{101\} \mathrm{d}$-spacing $(0.35 \mathrm{~nm})$ of the anatase $\mathrm{TiO}_{2}$. From the above discussion, it can be concluded that $\mathrm{MnW}_{12} / \mathrm{TiO}_{2}$ microflowers and nanorods are composed of $\mathrm{MnW}_{12}$ and $\mathrm{TiO}_{2}$. In order to further identify the components of the $\mathrm{MnW}_{12} / \mathrm{TiO}_{2}$ microflowers and nanorods, the corresponding EDX spectrum and element mapping were investigated (Figure S8 and Figure S9). The analyses evidently prove the presence of $\mathrm{Mn}, \mathrm{W}, \mathrm{Ti}, \mathrm{Na}$ and $\mathrm{O}$ components. Furthermore, the element mapping of $\mathrm{Mn}, \mathrm{W}, \mathrm{Ti}$, and $\mathrm{Na}$ shows a homogeneous distribution in the $\mathrm{MnW}_{12} / \mathrm{TiO}_{2}$ microflowers and nanorods.

\subsection{IR spectra}

Meanwhile, the IR spectra of $\mathrm{MnW}_{12} / \mathrm{TiO}_{2}$ microflowers, $\mathrm{MnW}_{12}$ and $\mathrm{MnW}_{12} / \mathrm{TiO}_{2}$ nanorods, $\mathrm{MnW}_{12}$-Air$550{ }^{\circ} \mathrm{C}$ were obtained between 400 and $4000 \mathrm{~cm}^{-1}$ using $\mathrm{KBr}$ pellets, which is very useful for the identification of the characteristic vibration bands of the POMs in the products. As depicted in Figure 3a, $\mathrm{MnW}_{12} / \mathrm{TiO}_{2}$ microflowers could be identified by three characteristic IR bands appearing at $864 \mathrm{~cm}^{-1}(\mathrm{v}$ $\left.\mathrm{WO}_{\mathrm{t}}\right), 812 \mathrm{~cm}^{-1}\left(\mathrm{v} \mathrm{W}_{2} \mathrm{O}\right.$, corner) and $661 \mathrm{~cm}^{-1}\left(\mathrm{v} \mathrm{W}_{2} \mathrm{O}\right.$, edge), which is in accordance with the bulk $\left[\mathrm{H}_{2} \mathrm{~W}_{12} \mathrm{O}_{40}\right]^{6-}$. And the bands at $913 \mathrm{~cm}^{-1}, 876 \mathrm{~cm}^{-1}, 812 \mathrm{~cm}^{-1}$ and $653 \mathrm{~cm}^{-1}$ for $\mathrm{MnW}_{12}$ are attributed to the vibration of the above $\mathrm{v}(\mathrm{W}-0)$ bonds. As shown in Figure $3 \mathrm{~b}$, The bands at 872,830 , and $702 \mathrm{~cm}^{-1}$ are observed for $\mathrm{MnW}_{12} / \mathrm{TiO}_{2}$ nanorods, which are attributed to the $\left(\mathrm{vWO}_{\mathrm{t}}\right),\left(\mathrm{v} \mathrm{W} \mathrm{W}_{2} \mathrm{O}\right.$, corner), and $\left(\mathrm{v} \mathrm{W} \mathrm{W}_{2} \mathrm{O}\right.$, edge) bonds, respectively. In addition, the occurrence of the characteristic vibration at 878, 799 and 727 $\mathrm{cm}^{-1}$ confirms the $\mathrm{v}(\mathrm{W}-\mathrm{O})$ bonds of $\mathrm{MnW}_{12}$-Air- $550^{\circ} \mathrm{C}$. These results indicate the building blocks of 
$\mathrm{MnW}_{12} / \mathrm{TiO}_{2}$ microflowers, $\mathrm{MnW}_{12}$ and $\mathrm{MnW}_{12} / \mathrm{TiO}_{2}$ nanorods, $\mathrm{MnW}_{12}$-Air-550 ${ }^{\circ} \mathrm{C}$ are all based on isopolyoxometallates $\left[\mathrm{H}_{2} \mathrm{~W}_{12} \mathrm{O}_{40}\right]^{6-}$ and the polyanions are preserved after calcining.

\subsection{XRD patterns}

The as-prepared $\mathrm{MnW}_{12} / \mathrm{TiO}_{2}$ microflowers, $\mathrm{MnW}_{12} / \mathrm{TiO}_{2}$ nanorods and their precursors were characterized by XRD. As can be seen from Figure $4 \mathrm{a}$, the main peaks of $\mathrm{MnW}_{12} / \mathrm{TiO}_{2}$ microflowers at $25.34^{\circ}, 36.06^{\circ}, 38.51^{\circ}, 47.98^{\circ}, 53.94^{\circ}, 55.05^{\circ}, 62.72^{\circ}$ and $68.94^{\circ}$ can be readily indexed to the anatase $\mathrm{TiO}_{2}$. According to the standard cards of anatase $\mathrm{TiO}_{2}$ (pdf no. 894921), the above-mentioned $2 \theta$ peaks are attributed to (101), (103), (112), (200), (105), (211), (204) and (116) crystal planes, respectively. And the peak of $\mathrm{MnW}_{12} / \mathrm{TiO}_{2}$ microflowers at $27.41^{\circ}$ is assigned to the (110) crystal plane of the rutile $\mathrm{TiO}_{2}$. The results reveal that the $\mathrm{P} 25-\mathrm{TiO}_{2}$ is preserved in the final product. Besides, the main $2 \theta$ peaks of $\mathrm{MnW}_{12} / \mathrm{TiO}_{2}$ microflowers at around $18.27^{\circ}, 23.67^{\circ}, 34.91^{\circ}, 37.42^{\circ}, 41.03^{\circ}, 52.03^{\circ}$ and $62.17^{\circ}$ can be readily indexed to the $\mathrm{MnW}_{12}$, which manifests $\mathrm{MnW}_{12}$ is the building block of the $\mathrm{MnW}_{12} / \mathrm{TiO}_{2}$ microflowers. As shown in Figure 4b, The main $2 \theta$ peaks of $\mathrm{MnW}_{12} / \mathrm{TiO}_{2}$ nanorods at around $25.35^{\circ}$, $48.23^{\circ}, 54.72^{\circ}$ and $63.09^{\circ}$ are assigned to the (101), (200), (105) and (204) crystal planes of anatase $\mathrm{TiO}_{2}$, respectively. In addition, the main peaks of $\mathrm{MnW}_{12} / \mathrm{TiO}_{2}$ nanorods at $18.37^{\circ}, 23.54^{\circ}, 29.87^{\circ}, 35.98^{\circ}$, $40.96^{\circ}, 44.17^{\circ}, 49.25^{\circ}, 51.25^{\circ}$ and $64.6^{\circ}$ can be readily indexed to the $\mathrm{MnW}_{12}$-Air-550 ${ }^{\circ} \mathrm{C}$. These results show that the composition of $\mathrm{MnW}_{12} / \mathrm{TiO}_{2}$ nanorods is definite, which consist of $\mathrm{TiO}_{2}$-Air- $550{ }^{\circ} \mathrm{C}$ and $\mathrm{MnW}_{12}$-Air-550 ${ }^{\circ} \mathrm{C}$.

\subsection{XPS spectra}

In addition, the XPS investigations on $\mathrm{MnW}_{12} / \mathrm{TiO}_{2}$ microflowers and $\mathrm{MnW}_{12} / \mathrm{TiO}_{2}$ nanorods were recorded to confirm the valence states of $\mathrm{Mn}, \mathrm{W}$ and $\mathrm{Ti}$. As the valence states of $\mathrm{Mn}, \mathrm{W}$ and $\mathrm{Ti}$ of $\mathrm{MnW}_{12} / \mathrm{TiO}_{2}$ microflowers and $\mathrm{MnW}_{12} / \mathrm{TiO}_{2}$ nanorods are the same (Figure S10), take $\mathrm{MnW}_{12} / \mathrm{TiO}_{2}$ nanorods as the example for detailed description. As depicted in Figure S10d, the peaks around 639.7 and $652.5 \mathrm{eV}$ in the energy regions of $\mathrm{Mn}_{2 \mathrm{p}}$ correspond to $\mathrm{Mn}^{2+}$ ions, indicating the existence of transition metal ion in this nanocomposites. As shown in Figure S10e, the peaks around 34.4 and $36.5 \mathrm{eV}$ in the energy regions of $\mathrm{W}_{4 \mathrm{f}}$ are confirmed to the $\mathrm{W}^{6+}$ centers in $\left[\mathrm{H}_{2} \mathrm{~W}_{12} \mathrm{O}_{40}\right]^{6-}$ building blocks. And the $\mathrm{Ti}_{2 \mathrm{p}}$ XPS peaks have a binding energy of $458.4 \mathrm{eV}$ and $464.4 \mathrm{eV}$, respectively, indicating that $\mathrm{Ti}^{4+}$ ion is incorporated into the nanorods (Figure S10f).

\subsection{TG analysis}

The Netzsch STA449F5 thermo-gravimetric analyzer was used for the thermal analysis in nitrogen dynamic atmosphere $(50 \mathrm{~mL} / \mathrm{min})$ at a heating rate of $10 \mathrm{~K} / \mathrm{min}$ and $19.2285 \mathrm{mg}$ powder of $\mathrm{MnW}_{12} / \mathrm{TiO}_{2}$ microflowers was thermally treated (Figure 5). The TG curve gives a total weight loss of $6.41 \%$ in the range of $23-1000{ }^{\circ} \mathrm{C}$. The weight loss of $2.68 \%$ during the first step from 23 to $164{ }^{\circ} \mathrm{C}$ corresponds to the 
release of adsorbed water molecules. On further heating, the second weight loss of $3.73 \%$ between $164-$ $290{ }^{\circ} \mathrm{C}$ is approximately attributed to the removal of structural water molecules.

\subsection{Photocatalytic hydrogen generation}

As depicted in Figure 6a, the hydrogen production of $\mathrm{MnW}_{12} / \mathrm{TiO}_{2}$ microflowers is $21.966 \mathrm{mmol} \mathrm{g}-1$, and the hydrogen production of $\mathrm{MnW}_{12} / \mathrm{TiO}_{2}$ nanorods is $28.684 \mathrm{mmol} \mathrm{g}-1$, after $5 \mathrm{hrs}$ of light irradiation. And it is calculated that the hydrogen production of $\mathrm{MnW}_{12} / \mathrm{TiO}_{2}$ nanorods is $30.58 \%$ higher than that of $\mathrm{MnW}_{12} / \mathrm{TiO}_{2}$ microflowers. The higher photocatalytic activity for $\mathrm{MnW}_{12} / \mathrm{TiO}_{2}$ nanorods than $\mathrm{MnW}_{12} / \mathrm{TiO}_{2}$ microflowers is probably due to the differences in morphologies of $\mathrm{MnW}_{12} / \mathrm{TiO}_{2}$, which will be explained from the following two aspects. On the one hand, the different morphologies of $\mathrm{MnW}_{12} / \mathrm{TiO}_{2}$ endow them different specific surface areas. As shown in Figure $6 \mathrm{c}, \mathrm{d}$ and Table 1, the specific surface area of $\mathrm{MnW}_{12} / \mathrm{TiO}_{2}$ nanorods is higher than that of $\mathrm{MnW}_{12} / \mathrm{TiO}_{2}$ microflowers. A larger specific surface area can provide more active sites, which contributes to the release of more hydrogen in the photocatalytic process. On the other hand, the morphology affects the separation efficiency and migration rate of photogenerated charges. Due to the quantum size effect, the particle size becomes smaller from microflowers to nanorods. In this case, charges separation effect and migration efficiency become higher, which leads to the improvement of catalytic activity. In short, the morphologies of $\mathrm{MnW}_{12} / \mathrm{TiO}_{2}$ are not alike, resulting in different photocatalytic hydrogen production capabilities. In addition, the stability test of $\mathrm{MnW}_{12} / \mathrm{TiO}_{2}$ nanorods showed that the total hydrogen production of three cycles were $28.051 \mathrm{mmol} / \mathrm{g}, 25.381 \mathrm{mmol} / \mathrm{g}$ and $25.332 \mathrm{mmol} / \mathrm{g}$, respectively (Figure 6b). After long-term illumination of 15 hours, the $\mathrm{MnW}_{12} / \mathrm{TiO}_{2}$ nanorods still maintain the corresponding catalytic activity. Meanwhile, there is no significant change in the XRD pattern of $\mathrm{MnW}_{12} / \mathrm{TiO}_{2}$ nanorods before and after three cycles of photocatalytic hydrogen generation (Figure S11). In all, the above confirm that $\mathrm{MnW}_{12} / \mathrm{TiO}_{2}$ nanorods have relatively favorable photocatalytic activity and cycle stability.

\section{Conclusion}

In summary, $\mathrm{MnW}_{12} / \mathrm{TiO}_{2}$ microflowers were successfully prepared by one-pot method under mild conditions. Moreover, the microflowers turn into nanorods though thermal treatment. The hydrogen production efficiency of $\mathrm{MnW}_{12} / \mathrm{TiO}_{2}$ nanorods is better than that of $\mathrm{MnW}_{12} / \mathrm{TiO}_{2}$ microflowers through the photocatalytic hydrogen production test. The difference in photocatalytic performance is attributed to the difference in morphology. Meanwhile, a large number of control experiments have also been explored to clarify the reasons for the transformation of morphology. Thus, the successful preparation of $\mathrm{MnW}_{12} / \mathrm{TiO}_{2}$ microflowers and nanorods enrichs the structural diversity of isopolyoxometallate based nano/micro materials. And this method reported in this work is proposed to be a general process to improve the photocatalytic efficiency of $\mathrm{POM} / \mathrm{TiO}_{2}$ nano/micro composite.

\section{Declarations}




\section{Authors'Contributions}

Conceptualization-investigation: N.G., G.W. and Y.Z.; writing-review and editing: N.G. and G.W.; validation: S.L., N.Z., X.W.; funding acquisition: G.W.. All authors have approved the final version of the manuscript.

\section{Funding}

This work was supported by the Natural Science Foundation of China (Grants: 21901061 and U1504201). The authors are grateful to the Program for Science \& Technology Innovation Talents in Universities of Henan Province (19HASTIT004) and the Program for Innovation Teams in Science and Technology in Universities of Henan Province (20IRTSTHN004).

\section{Availability of Data and Materials}

Data sharing is not applicable to this article as no datasets were generated or analyzed during the current study.

\section{Competing interests}

The authors declare that they have no conflict of interests.

\section{References}

[1] Yamase, T. (1998). Photo- and electrochromism of polyoxometalates and related materials. Chem. Rev. 98: 307-325.

[2] Long, D.L.; Burkholder, E.; Cronin, L. (2007). Polyoxometalate clusters, nanostructures and materials: from self-assembly to designer materials and devices. Chem. Soc. Rev. 36: 105-121.

[3] Mizuno, N.; Yamaguchi, K.; Kamata, K. (2005). Epoxidation of olefins with hydrogen peroxide catalyzed by polyoxometalates. Coord. Chem. Rev. 249: 1944-1956.

[4] Song, Y.F.; Tsunashima, R. (2012). Recent advances on polyoxometalate-based molecular and composite materials. Chem. Soc. Rev. 41: 7384-7402.

[5] Liu, T.B.; Diemann, E.; Li, H.L.; Dress, A.W.M.; Müller, A. (2003). Self-assembly in aqueous solution of wheel-shaped $\mathrm{Mo}_{154}$ oxide clusters into vesicles. Nature, 426: 59-62.

[6] Zhang, L.J.; Webster, T.J. (2009). Nanotechnology and nanomaterials: promises for improved tissue regeneration. Nanotoday 4: 66-80.

[7] Cooper, G.J.T.; Boulay, A.G.; Kitson, P.J.; Ritchie, C.; Richamond, C.J.; Thiel, J.; Gabb, D.; Eadie, R.; Long, D.L.; Cornin, L. (2011). Osmotically driven crystal morphogenesis: a general approach to the fabrication of 
micrometer-scale tubular architectures based on polyoxometalates. J. Am. Chem. Soc. 133: 5947-5954.

[8] Shen, Y.; Peng, J.; Zhang, H.Q.; Yu, X. (2012). Mo-substituted Keggin tungstosilicate microtubes: preparation and characterization. Inorg. Chem. 51: 5146-5151.

[9] Wang, G.; Meng, R.R.; Yang, J.; He, X.M.; Chen, J.J.; Zhang, D.D.; Xu, X.X.; Niu, J.Y. (2019). Shape-control of $\mathrm{CeF}_{3}$ nanocrystals by doping polyoxometalates: syntheses, characterization and tunable photoluminescence. Chem. Commun. 55: 1619-1622.

[10] Wang, G.; Wang, Y.K.; Meng, R.R.; Xu, X.X.; Niu, J.Y. (2018). Synthesis and spectroscopic properties of silver-fluorescein co-doped phosphotungstate hollow spheres. Dalton. Trans. 47: 7730-7738.

[11] Bhattacharjee, K.; Chattopadhyay, K.K.; Das, G.C. (2015). Unconventional dexter-silverton type manganese heteropolytungstate $\left[\mathrm{Mn}_{7}\left(\mathrm{MnW}_{12} \mathrm{O}_{42}(\mathrm{OH})_{4} \cdot 8 \mathrm{H}_{2} \mathrm{O}\right)\right]$ hollow microsphere: synthesis, crystal structure, growth mechanism, and optical property study. J. Phys. Chem. C. 119: 1536-1547.

[12] Schattka, J.H.; Shchukin, D.G.; Jia, J.G.; Antonietti, M.; Caruso, R.A. (2002). Photocatalytic activities of porous titania and titania/zirconia structures formed by using a polymer gel templating technique. Chem. Mater. 14: 5103-5108.

[13] Luo, H.M.; Takata, T.; Lee, Y.; Zhao, J.F.; Domen, K.; Yan, Y.S. (2004). Photocatalytic activity enhancing for titanium dioxide by co-doping with bromine and chlorine. Chem. Mater. 16: 846-849.

[14] Parayil, S.K.; Lee, Y.M.; Yoon, M. (2009). Photoelectrochemical solar cell properties of heteropolytungstic acid-incorporated $\mathrm{TiO}_{2}$ nanodisc thin films. Electrochemistry Communications 11: $1211-1216$.

[15] Xu, Y.F.; Zhang, C.; Zhang, L.X.; Zhang, X.H.; Yao, H.L.; Shi, J.L. (2016). Pd-catalyzed instant hydrogenation of $\mathrm{TiO}_{2}$ with enhanced photocatalytic performance. Energy Environ. Sci. 9: 2410-2417.

[16] AlSalka, Y.; Hakki, A.; Schneider, J.; Bahnemann, D.W. (2018). Co-catalyst-free photocatalytic hydrogen evolution on $\mathrm{TiO}_{2}$ : synthesis of optimized photocatalyst through statistical material science. Appl. Catal. B Environ. 238: 422-433.

[17] Hu, L.S.; Li, Y.; Zheng, W.R.; Peng, Y.K.; Tsang, S.C.E.; Lee, L.Y.S.; Wong, K.Y. (2020). Blue ordered/disordered Janus-type $\mathrm{TiO}_{2}$ nanoparticles for enhanced photocatalytic hydrogen generation. J. Mater. Chem. A 8: 22828-22839.

[18] Pan, L.; Wang, S.B.; Xie, J.W.; Wang, L.; Zhang, X.W.; Zou, J.J. (2016). Constructing $\mathrm{TiO}_{2}$ p-n homojunction for photoelectrochemical and photocatalytic hydrogen generation. Nano Energy 28: 296303. 
[19] Yue, X.Z.; Li, C.Q.; Liu, Z.Y.; Yi, S.S.; Chen, D.L.; Wang, F.; Li, S.H. (2019). Steering charge kinetics in $\mathrm{W}_{2} \mathrm{C} @ \mathrm{C} / \mathrm{TiO}_{2}$ heterojunction architecture: efficient solar-light-driven hydrogen generation. Appl. Catal. B Environ. 255: 117760-117769.

[20] Pearson, A.; Bhosale, S.; Bhargava, S.K.; Bansal, V. (2013). Combining the UV-switchability of Keggin ions with a galvanic replacement process to fabricate $\mathrm{TiO}_{2}$-polyoxometalate-bimetal nanocomposites for improved surface enhanced raman scattering and solar light photocatalysis. ACS Appl Mater Interfaces 5: 7007-7013.

[21] Shi, H.F.; Yu, Y.C.; Zhang, Y.; Feng, X.J.; Zhao, X.Y.; Tan, H.Q.; Khan, S.U.; Li, Y.G.; Wang, E.B. (2018). Polyoxometalate/ $\mathrm{TiO}_{2} / \mathrm{Ag}$ composite nanofibers with enhanced photocatalytic performance under visible light. Appl. Catal. B Environ. 221: 280-289.

[22] An, X.Q.; Tang, Q.W.; Lan, H.C.; Liu, H.J.; Qu, J.H. (2019). Polyoxometalates/TiO ${ }_{2}$ Fenton-like photocatalysts with rearranged oxygen vacancies for enhanced synergetic degradation. Appl. Catal. B Environ. 244: 407-413.

\section{Tables}

Table 1. The specific surface area and pore size of $\mathrm{MnW}_{12} / \mathrm{TiO}_{2}$ microflowers and $\mathrm{MnW}_{12} / \mathrm{TiO}_{2}$ nanorods.

\begin{tabular}{|lll|}
\hline Sample & Specific surface area $\left(\mathrm{m}^{2} / \mathbf{g}\right)$ & pore size $(\mathrm{nm})$ \\
\hline $\mathrm{MnW}_{12} / \mathrm{TiO}_{2}$ microflowers & 24.592 & 3.820 \\
$\mathrm{MnW}_{12} / \mathrm{TiO}_{2}$ nanorods & 29.302 & 3.817 \\
\hline
\end{tabular}

\section{Figures}



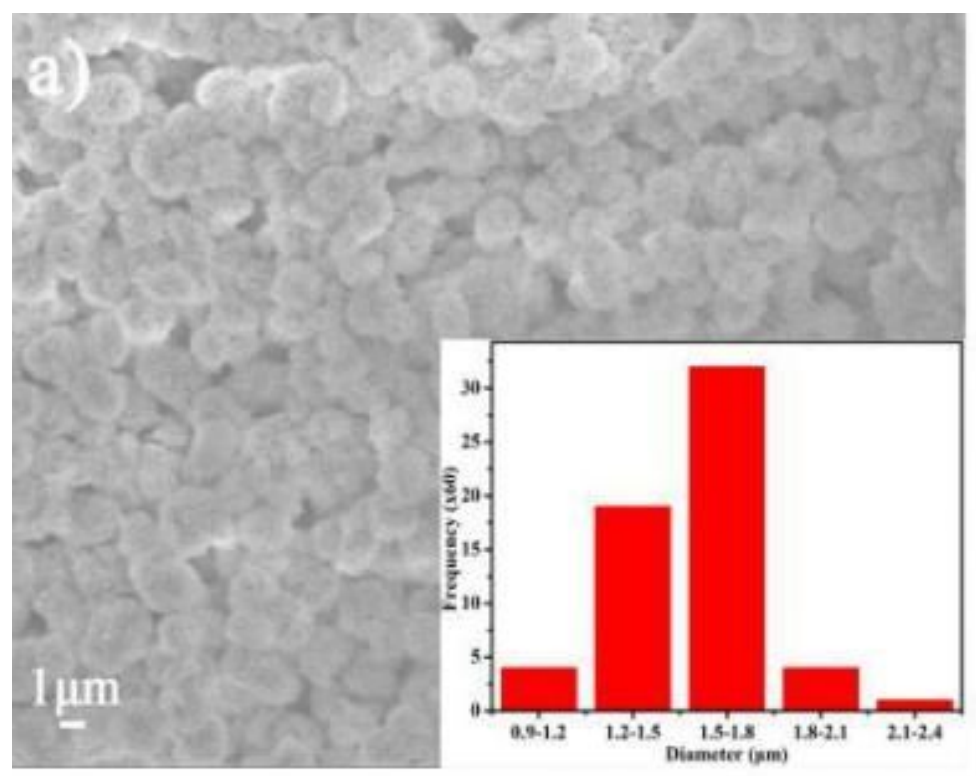

c)

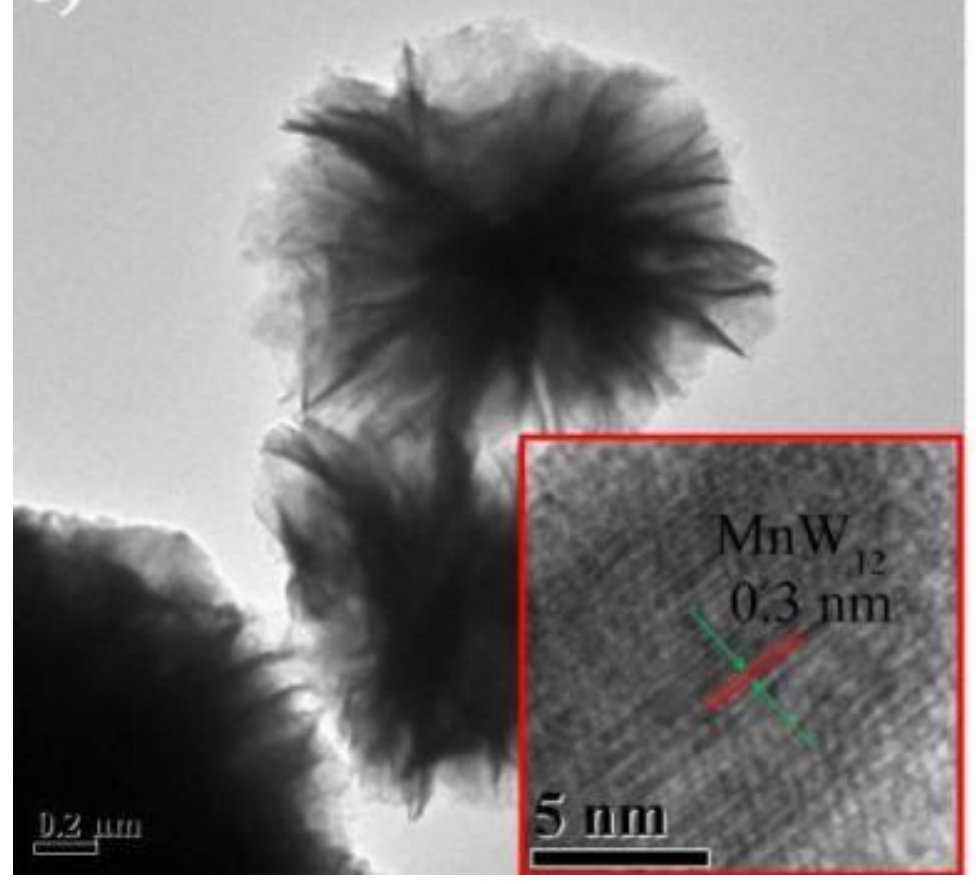

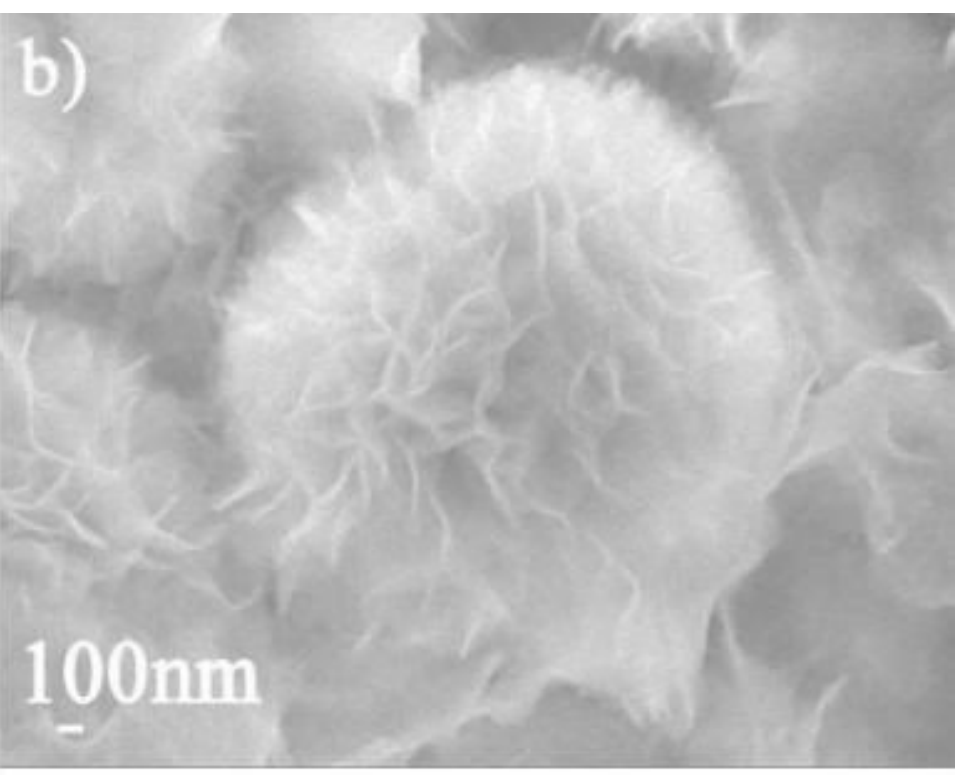

d)

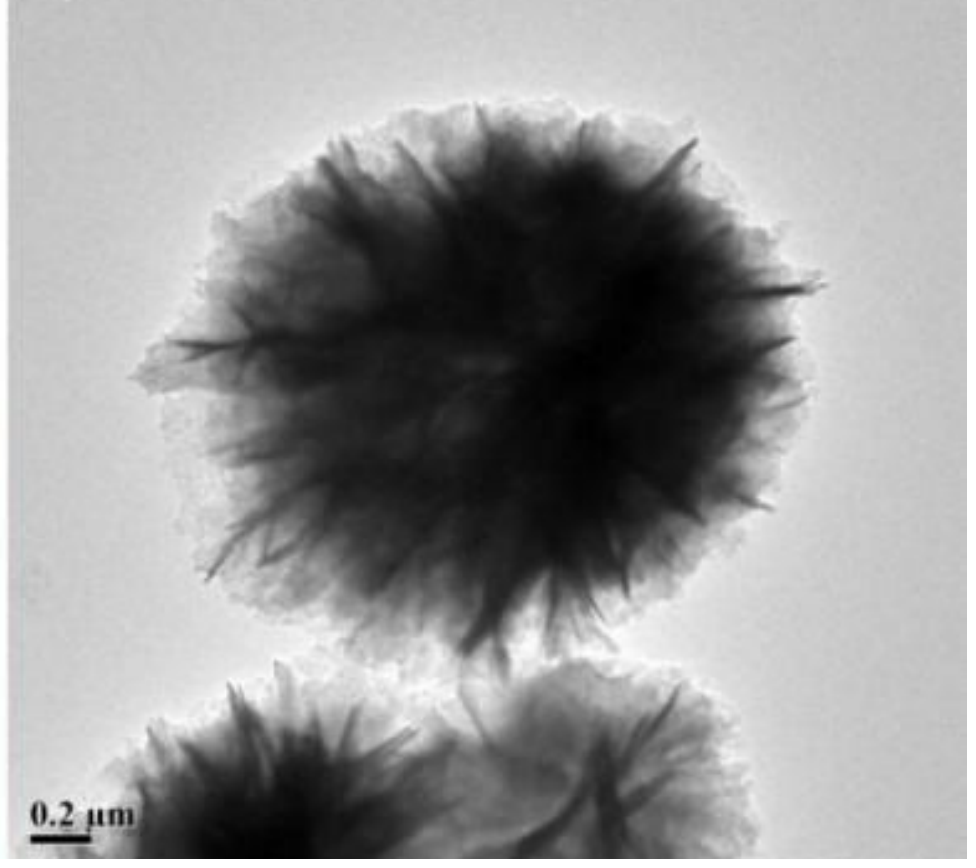

Figure 1

( $a$ and b) SEM images of MnW12 microflower with different resolutions, inset: size distribution of MnW12 microflower; (c and d) TEM/HRTEM images of MnW12 microflower. 

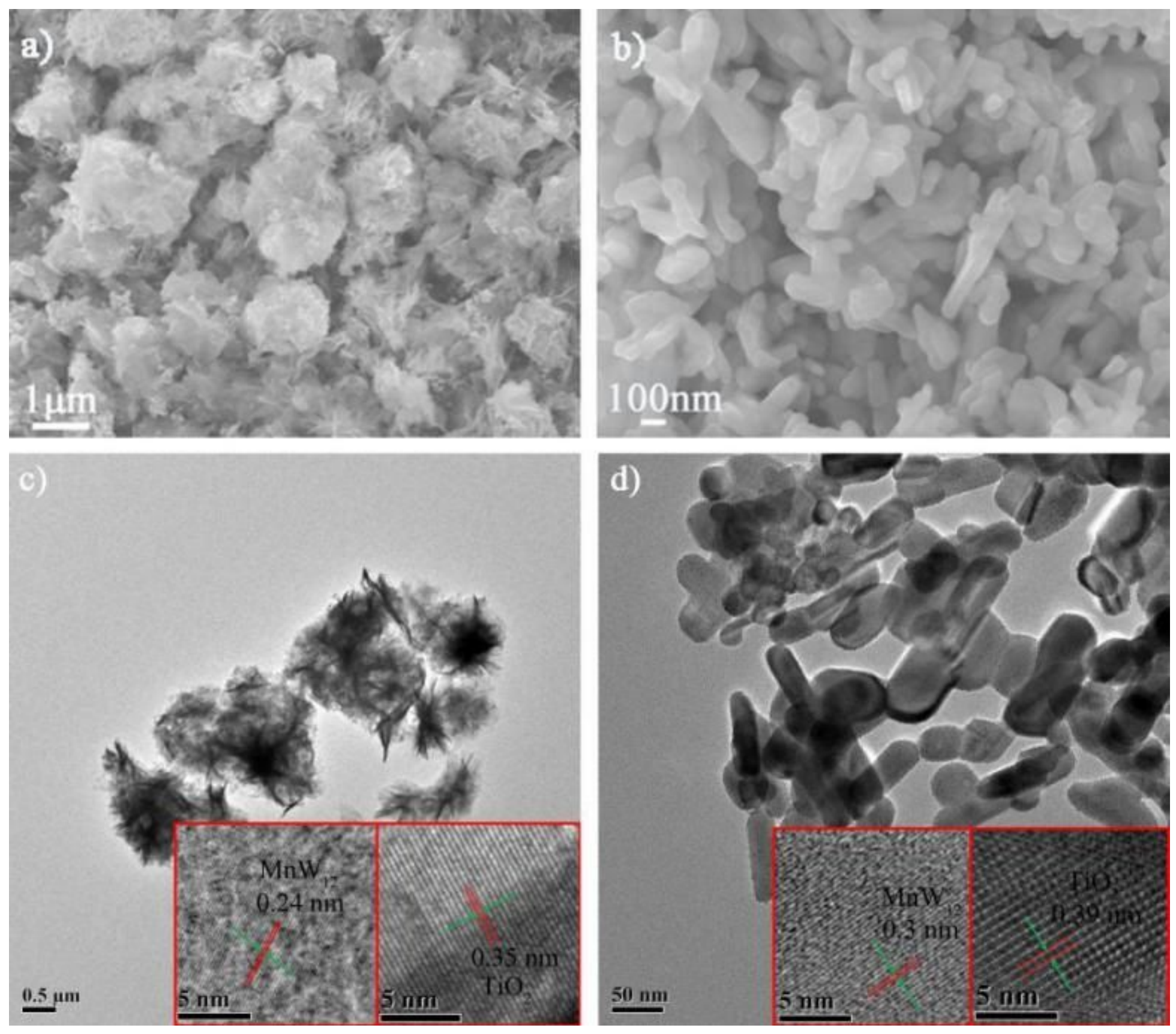

\section{Figure 2}

(a and b): SEM images of MnW12/TiO2 microflowers (a) and MnW12/TiO2 nanorods (b); (c and d): TEM/HRTEM images of MnW12/TiO2 microflowers (c) and MnW12/TiO2 nanorods (d). 

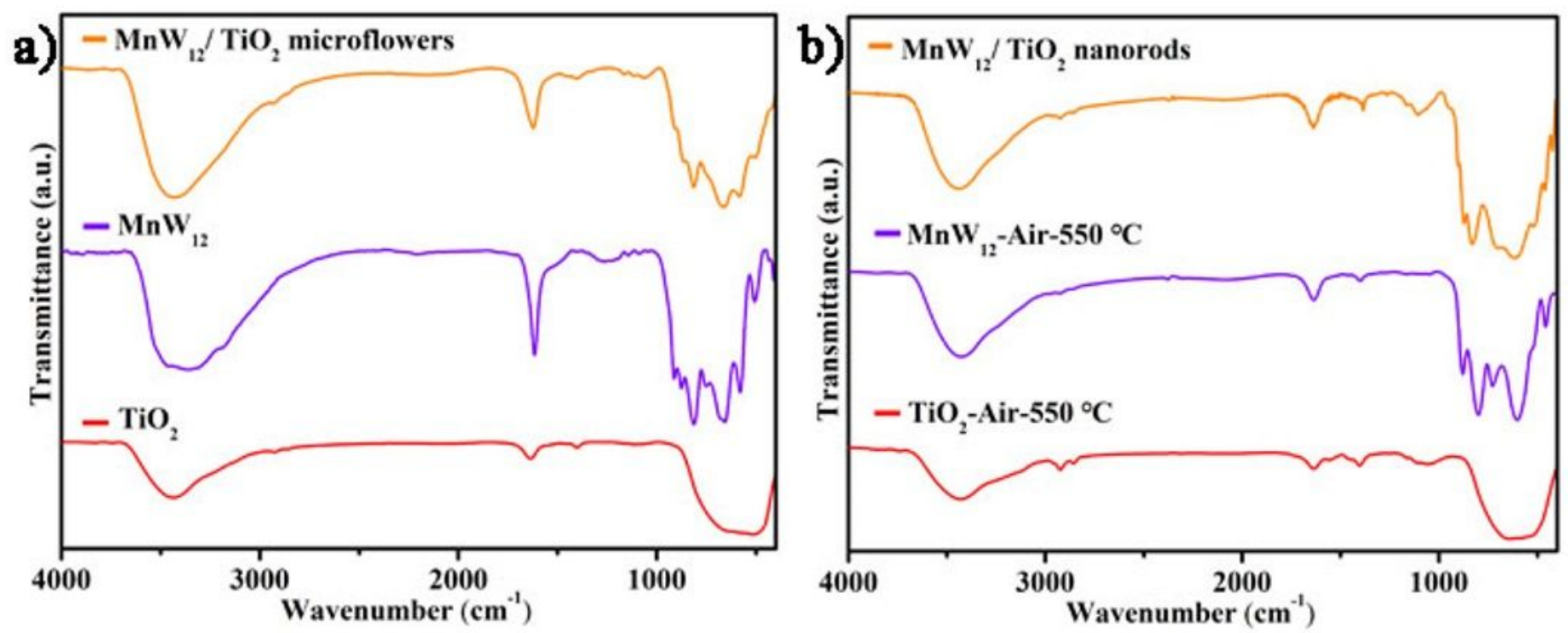

Figure 3

(a): The IR spectra of MnW12/TiO2 microflowers, MnW12 and TiO2; (b): the IR spectra of MnW12/TiO2 nanorods, MnW12-Air-550 ${ }^{\circ} \mathrm{C}$ and TiO2-Air-550 ${ }^{\circ} \mathrm{C}$.
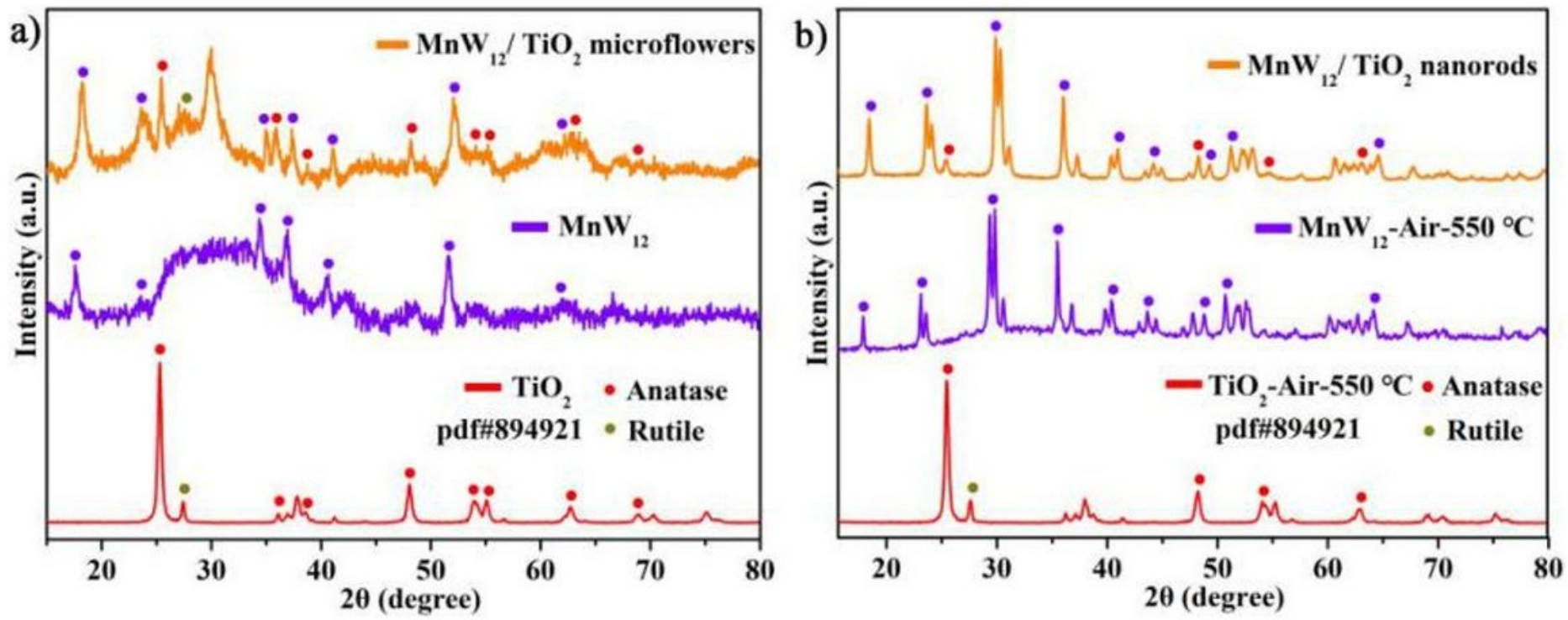

Figure 4

(a): The XRD pattern of MnW12/TiO2 microflowers, MnW12 and TiO2; (b): the XRD pattern of MnW12/TiO2 nanorods, MnW12-Air-550 ${ }^{\circ} \mathrm{C}$ and TiO2-Air-550 ${ }^{\circ} \mathrm{C}$. 


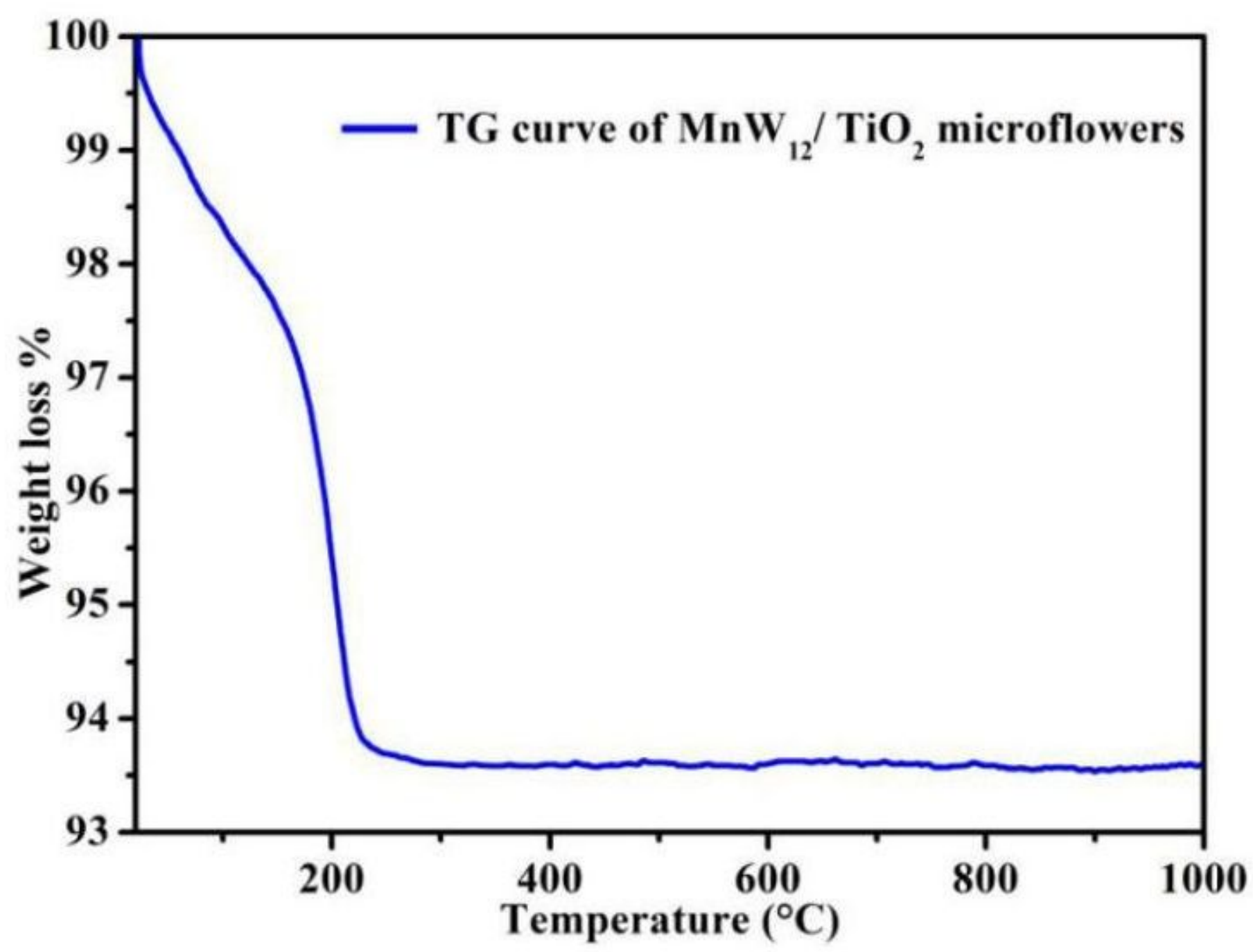

Figure 5

The TG spectra of MnW12/TiO2 microflowers. 

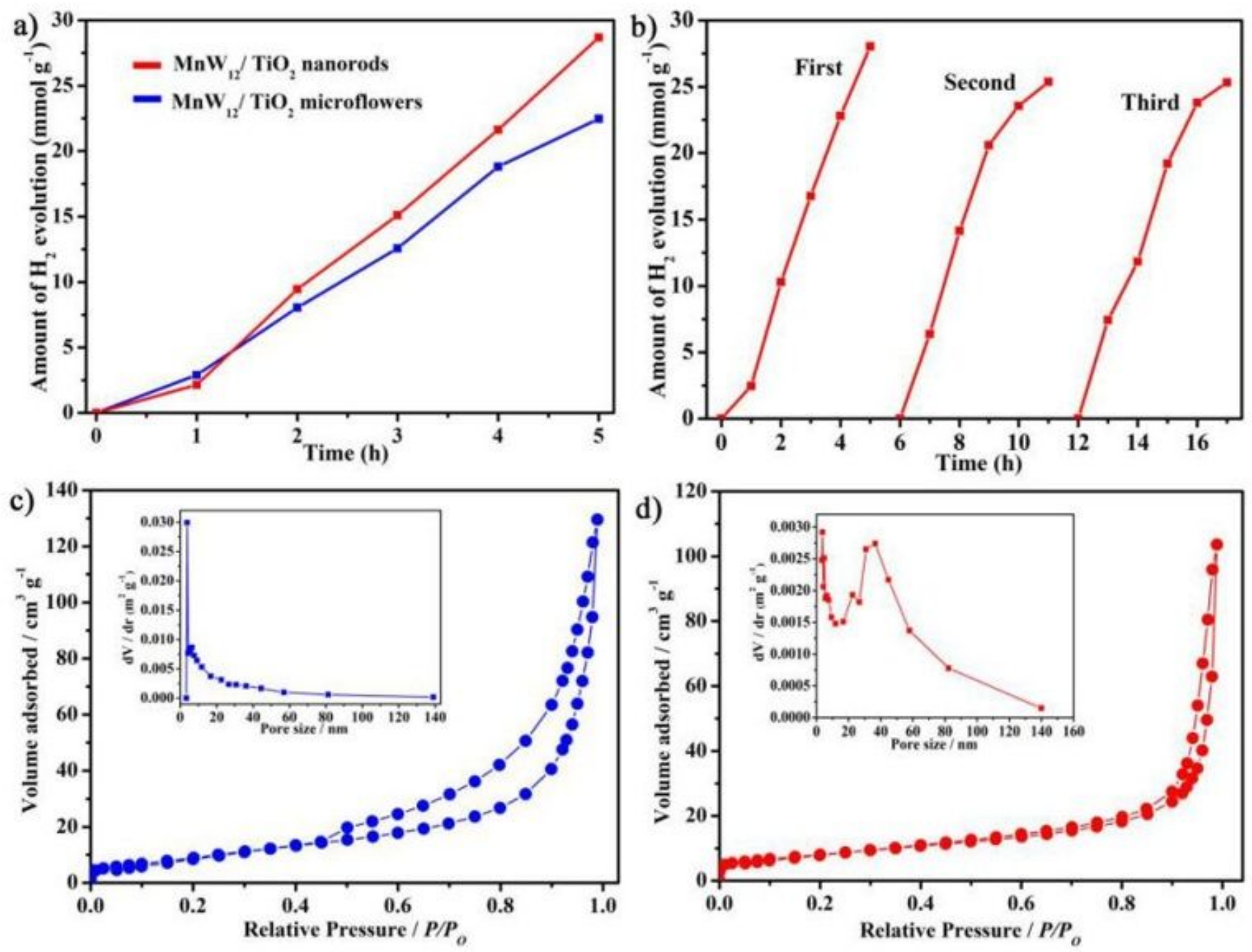

Figure 6

(a): Time course of photocatalytic hydrogen generation between MnW12/TiO2 microflowers and MnW12/TiO2 nanorods; (b): Photocatalytic hydrogen generation of MnW12/TiO2 nanorods with intermittent evacuation every $5 \mathrm{~h}$; (c and d): N2 adsorption-desorption isotherm of MnW12/TiO2 microflowers (c) and MnW12/TiO2 nanorods (d), (inset: the corresponding pore size distribution curve).

\section{Supplementary Files}

This is a list of supplementary files associated with this preprint. Click to download.

- Scheme1.jpeg

- SupportingInformation.docx 